\title{
Estilos de enfrentamento religioso em mulheres acometidas por câncer de mama
}

\section{Religious coping styles among breast cancer patients}

\author{
Carolina de Resende Damas Cardoso* \\ Universidade de São Paulo - USP, Ribeirão Preto, São Paulo, Brasil
}

\section{Rodrigo Sanches Peres**}

Universidade Federal de Uberlândia - UFU, Uberlândia, Minas Gerais, Brasil

\section{Introdução}

De acordo com Faria e Seidl (2005), o termo "enfrentamento religioso" refere-se basicamente à utilização da religiosidade no manejo de situações estressoras, dentre as quais se destaca o surgimento de doenças graves. As Ciências da Saúde, de modo geral, têm se voltado a esse assunto principalmente a partir dos anos 1990, motivadas pelo surgimento de constatações empíricas de que a religiosidade se encontra associada - positiva ou negativamente - a indicadores de qualidade de vida e bem-estar (PANZINI; BANDEIRA, 2007). Porém, ainda são escassos os estudos nacionais dedicados especificamente a essa temática.

É preciso esclarecer que a religiosidade oferece uma variedade de estilos de enfrentamento, cujos efeitos podem favorecer ou dificultar a adaptação do indivíduo. A literatura científica especializada destaca cinco estilos de enfrentamento religioso: súplica, renúncia, autodireção, delegação e colaboração (PANZINI; BANDEIRA, 2007). Ambos podem ser utilizados, em diferentes níveis e com diferentes efeitos, por pacientes oncológicos. Afinal, nessa população, segundo Fornazari e Ferreira (2010), o enfrentamento religioso é comum em função dos estigmas associados ao câncer.

O câncer de mama, conforme Gonçalves, Giglio e Ferraz (2005), pode ser considerada a doença mais temida pelas mulheres. Isso acontece porque, além de ser a neoplasia maligna mais frequente e uma das principais causas de morte na população feminina de diversos países, atinge o principal símbolo corpóreo da feminilidade, da sensualidade e da maternidade (CAETANO; GRADIM; SANTOS, 2009). Levando em consideração tais fatos, uma pesquisa vem sendo realizada para delinear o impacto psicológico da doença. O presente estudo é um recorte dessa pesquisa e tem como objetivo identificar os estilos de 
enfrentamento religioso predominantemente adotados no manejo das repercussões do câncer de mama por mulheres acometidas pela doença.

\section{Método}

Trata-se de um estudo quantitativo, de natureza descritiva e exploratória. Foi empregada uma amostra de conveniência $(n=72)$, composta pelas participantes de 18 sessões de um grupo de apoio psicológico oferecido gratuitamente a mulheres acometidas por câncer de mama em um hospital universitário. Após a aprovação de um Comitê de Ética em Pesquisa, os relatos apresentados espontaneamente por tais mulheres no contexto do grupo de apoio foram analisados com 0 intuito de identificar os estilos de enfrentamento religioso adotados no manejo das repercussões da doença. O presente estudo, portanto, tem um enfoque naturalístico, na medida em que descreve um fenômeno assim como ele naturalmente ocorre e nas circunstâncias que espontaneamente 0 geram.

\section{Resultados: apresentação e discussão}

Algumas pacientes apresentaram dois ou mais relatos indicativos da utilização de dois ou mais estilos de enfrentamento religiosos. Assim, foram identificados, no total, 76 relatos, os quais foram apresentados por 29 das pacientes que compuseram a amostra. Os estilos mais frequentes foram a delegação, identificada em 31 relatos de 22 pacientes, e a colaboração, identificada em 25 relatos de 14 pacientes. O emprego da delegação leva o indivíduo a passivamente outorgar a Deus sua responsabilidade no que se refere à solução das situações estressoras, de modo que, conforme Faria e Seidl (2005), tende a gerar consequências prejudiciais. Já o emprego da colaboração geralmente proporciona efeitos benéficos, pois faz com que o indivíduo ativamente assuma corresponsabilidade com Deus (Pargament; Smith; Koenig; Perez, 1998).

Como revelam Panzini e Bandeira (2007), muitos estudos internacionais evidenciam que o emprego de estilos de enfrentamento religioso que - a exemplo da colaboração tendem a favorecer a adaptação do indivíduo - é mais frequente diante de problemas relacionados à saúde em diferentes populações. Porém, em um estudo realizado especificamente com mulheres acometidas por câncer de mama, Hebert, Zdaniuk, Schulz e Scheier (2009) não verificaram associação positiva entre a colaboração e a presença de 
indicadores de bem-estar. Além disso, constataram que a delegação é um preditor de importantes problemas de saúde mental.

A revisão bibliográfica realizada para os fins do presente estudo conduziu à localização de apenas duas pesquisas publicadas em periódicos científicos nacionais indexados (CAETANO; GRADIM; SANTOS, 2009; GONÇALVES; GÍGLIO; FERRAZ, 2005) que exploram a utilização da religiosidade no manejo das situações estressoras provocadas pelo câncer de mama. Ambas apontam que a religiosidade auxiliou a minimizar o desespero, a angústia e a depressão na maioria das mulheres avaliadas, levando-as a assumir uma postura mais ativa em relação ao tratamento. Tais achados contrastam com os resultados do presente estudo. Entretanto, nas pesquisas em questão não foram especificados quais foram os estilos de enfrentamento religiosos predominantes.

\section{Considerações finais}

Devido à sua complexidade, o assunto em questão demanda novos estudos, sobretudo visando a identificar os fatores e efeitos associados à utilização de cada um dos distintos estilos de enfrentamento religioso nessa população. De qualquer forma, os resultados apresentados nessa oportunidade apontam que mulheres acometidas por câncer de mama podem utilizar, com frequência expressiva, estilos de enfrentamento religioso potencialmente prejudiciais à superação das dificuldades inerentes a cada uma das etapas que se sucedem do diagnóstico à reabilitação. Obviamente tal achado se refere a uma amostra específica. Ainda assim, evidencia que os profissionais de saúde envolvidos com a assistência a pacientes oncológicos devem dedicar atenção especial ao emprego da religiosidade no manejo das situações estressoras desencadeadas pela vivência da doença para que seus aspectos adaptativos não sejam supervalorizados.

\section{Referências}

CAETANO, E. A.; GRADIM, C. V. C.; SANTOS, L. E. S. Câncer de mama: reações e enfrentamento ao receber o diagnóstico. Revista de Enfermagem da UERJ, Rio de Janeiro, v. 17, n. 2, p. 257-261, 2009.

FARIA, J. B.; SEIDL, E. M. F. Religiosidade e enfrentamento em contextos de saúde e doença: revisão da literatura. Psicologia: Reflexão e Crítica, Porto Alegre, v. 18, n. 3, p. 381-389, 2005. 
FORNAZARI, S. A.; FERREIRA, R. E. R. Religiosidade/espiritualidade em pacientes oncológicos: qualidade de vida e saúde. Psicologia: Teoria e Pesquisa, Brasília, v. 26, n. 2, p. 265-272, 2010. GONÇALVES, M.; GÍGLIO, J. S.; FERRAZ, M. P. T. A. Religiosidade como fator de proteção contra depressão em pacientes com neoplasia mamária. Arquivos Brasileiros de Psiquiatria, Neurologia e Medicina Legal, Rio de Janeiro, v. 99, n. 4, p. 16-20, 2005.

HEBERT, R.; ZDANIUK, B.; SCHULZ, R.; SCHEIER, M. Positive and negative religious coping and well-being in women with breast cancer. J ournal of Palliative Medicine, New York, v. 12, n. 6, p. 537-545, 2009.

PANZINI, R., G.; BANDEIRA, D. R. Coping (enfrentamento) religioso/espiritual. Revista de Psiquiatria Clínica, São Paulo, v. 34, n. 1, p. 126-135, 2007.

PARGAMENT, K. I.; SMITH, B. W.; KOENIG, H. G.; PEREZ, L. Patterns of positive and negative religious coping with major life stressors. J ournal for the Scientific Study of Religion, Hoboken, v. 37, n. 4, p. 710-724, 1998.

\section{Endereço para correspondência}

Carolina de Resende Damas Cardoso

Rua Lafaiete, 898/Apto 124. Centro. Ribeirão Preto - SP. CEP 14015-080

Endereço eletrônico: cmrdc@hotmail.com

\section{Rodrigo Sanches Peres}

Instituto de Psicologia - Universidade Federal de Uberlândia. Avenida Pará, 1720 Bloco 2C

Campus Umuarama. Uberlândia - MG. CEP 38405-320

Endereço eletrônico: rodrigosanchesperes@yahoo.com.br

Recebido em: 04/07/2011

Aceito para publicação em: 18/11/2011

Acompanhamento do processo editorial: 18/11/2011

Notas

* Psicóloga, mestranda em Psicologia. Universidade de São Paulo.

**Psicólogo, mestre e doutor em Psicologia. Universidade Federal de Uberlândia, Uberlândia, Brasil. 